\title{
Correlation between dietary intake and serum ganglioside concentrations: a cross- sectional study among Malaysian toddlers
}

Geok Lin Khor ${ }^{1 *}$, Sangeetha Shyam¹, Snigdha Misra', Bertram Fong², Megan Hueh Zan Chong ${ }^{1}$, Norhasmah Sulaiman ${ }^{3}$, Yee Lin Lee ${ }^{3}$, Rebecca Cannan ${ }^{2}$ and Angela Rowan ${ }^{2}$

\begin{abstract}
Background: Gangliosides are a group of sialylglycosphingolipids, widely distributed in body tissues, mainly as components of plasma membranes. They play crucial roles in neurodevelopment, gut maturation, and immune system. Dietary gangliosides have been shown to bring about benefits including cognition and immune support for breastfed infants. There is dearth of studies on dietary gangliosides intake or plasma ganglioside levels for toddlers. Given toddlers are still growing rapidly, a good understanding of ganglioside intake during this early childhood period is important for future dietary recommendations. The aim of this study was to provide information on dietary ganglioside intake in Malaysian toddlers and correlations with serum ganglioside levels.
\end{abstract}

Methods: Toddlers who fulfilled the inclusion criteria were recruited from the Federal Territory of Putrajaya and neighboring urban suburbs. Background characteristics and food intake using food frequency questionnaire were collected for the entire sample $(n=153)$. As for ganglioside correlation determination, a 2 day weighed food record was conducted on a sub-group who provided blood $(n=74)$. Ganglioside levels in the food and blood were determined using modern high performance liquid chromatography mass spectrometry method.

Results: The average dietary intake of total gangliosides for the Malaysian toddlers (aged 12-24.5 months) was 5.86 $\pm 0.56 \mathrm{mg} / \mathrm{day}$. Growing up milks had a wide ganglioside concentration range $(0.0311 .4 \mathrm{mg} / 100 \mathrm{~g})$, and were the major contributor to dietary ganglioside intake (85\%). The remaining dietary gangliosides were provided by other dairy products, meat, fish, bakery and biscuits.

Serum levels varied from $5.05 \mu \mathrm{g} / \mathrm{mL}$ to $16.15 \mu \mathrm{g} / \mathrm{mL}$. While no significant correlation was observed between dietary ganglioside intake from growing up milks and serum ganglioside levels in the toddlers, there was a significant but weak correlation between dietary ganglioside intake from dairy products $(r=0.241 ; p=0.038)$ and meat $(r=0.294 ; p=0.010)$ with serum ganglioside levels

Conclusions: Gangliosides are a component of the Malaysian toddlers' diet ( $5.68 \pm 0.56 \mathrm{mg} /$ day), and were measured in their plasma at levels ranging from 5.05 to $16.15 \mu \mathrm{g} / \mathrm{mL}$. Growing up milk contributed to $85 \%$ of the total dietary gangliosides intake, with remaining contributions from chicken meat and fish. More studies should be undertaken on the contributions of dietary gangliosides, including breast milk, in bringing about health benefits to young children.

\footnotetext{
* Correspondence: khor.geoklin@gmail.com

${ }^{1}$ Department of Nutrition and Dietetics, International Medical University,

Kuala Lumpur 57000, Malaysia

Full list of author information is available at the end of the article
} 


\section{Background}

Gangliosides are a group of sialic acid glycosphingolipids, which are complex bio-active lipids, widely distributed in body tissues mainly as components of plasma membranes. They are found predominately in nervous tissue and are particularly abundant in the brain, forming $10-12 \%$ of the lipid matter [1]. The brain grows rapidly, much faster than that of other body tissue, and by 2 years of age, the brain reaches about $80 \%$ of its adult weight. During these neuro-development processes, gangliosides are believed to play a crucial role in synaptic networking, dendritic branching and cell multiplication and migration [2].

In light of its crucial roles in pre- and postnatal development of the brain, particularly during the critical windows of rapid brain growth, differentiation and lipid accumulation, interest has grown for gangliosides as a dietary component [3]. Exogenous administration of sialic acid, either bound or free, in animal model studies, has been shown to increase sialic acid concentrations in gangliosides and glycoproteins of the animal brain leading to improved learning [4-7]. Similarly, cow-milk-derived glycomacropeptide, a source of sialic acid, was reported to increase sialylation in brain glycoproteins and gangliosides, leading to a positive influence on cognition in animal models [8]. In developing rats, dietary sialic acid was confirmed to increase cortical ganglioside sialic acid in a dose-response manner [9]. Reis et al. [10] provided further evidence that consumption of bovine gangliosides affects the biosynthesis of specific brain gangliosides based on a piglet model.

Dietary gangliosides have also been shown to protect the gastrointestinal tract from bacteria and inflammation [11]. These authors postulated that dietary gangliosides could act as a physiological barrier for protection against enteric infections through changing the lipid profile and structure of the developing intestinal microdomains.

Gangliosides have been isolated from animal food sources including milk, meat, eggs, organ meat, egg yolks, chicken livers and animal fat tissues [12-16]. Foods of plant origin are not a source of gangliosides as they lack the pathway to synthesize sialic acid [7]. Estimates of ganglioside contents in human milk ranged between 1.7 and $68.6 \mathrm{mg} / \mathrm{L}$ [17-20], while that for reconstituted infant formula is about $2-16 \mathrm{mg} / \mathrm{L}$ [20-23]. Infants receiving bovine-based milk formula are reported to ingest as little as $20 \%$ of the ganglioside consumed by exclusively breastfed infants [22]. Significantly higher sialic acid levels have been reported in the frontal cortex gangliosides and glycoproteins of human milk-fed compared with standard formula-fed infants in the first year of life [8].

Only one study to date reported the ganglioside concentration in a limited number of foods (milk, yoghurt, beef, tuna and egg), and was used to estimate the ganglioside intake for a small population group [24]. However, the ganglioside concentrations in the foods and the estimated ganglioside intake was quantified as lipid bound sialic acid (LBSA) equivalent, making it difficult to relate this back to the actual ganglioside concentration.

Similarly, there is a paucity of data on consumption of gangliosides in young children and its association to serum ganglioside levels. In light of emerging evidence of neuro-developmental and intestinal health benefits conferred by dietary gangliosides in early childhood, this study was undertaken to investigate the relationship between dietary intake and serum concentrations of gangliosides among toddlers. Gangliosides in the dietary foods and in serum were measured directly using modern high performance liquid chromatography-mass spectrometry method.

\section{Methods}

\section{Study design and subjects}

A cross-sectional study was undertaken with the objectives to determine (i) the dietary intake of gangliosides among Malaysian toddlers; (ii) their serum ganglioside status, and (iii) the association between dietary intake and serum ganglioside levels of the toddlers. Subjects were recruited from licensed ${ }^{1}$ day care centres located in the Federal Territory of Putrajaya and neighbouring urban suburbs. Licensed day care centres are required to provide food and beverages according to guidelines recommended by the Ministry of Health, Malaysia. Non-licensed centres are considered illegal by the government as they may not conform to the criteria and recommendations of the government regarding safety and cleanliness of premises, caregiver to child ratio, and food preparation guidelines.

Approximately 100 day care centres in the Federal Territory of Putrajaya and neighbouring urban suburbs were approached to take part in the study. However, many did not agree, citing reasons as they were too busy, study would disturb the children, and parents did not agree to taking of blood from their children. Eventually, the management of 21 centres gave permission, and appointments were made with parents/care givers for the briefing of the study. Parents who agreed to participate, signed the informed consent form. Through the 'snowballing' method, toddlers who fulfilled the study's inclusion criteria were included in the study.

\section{Inclusion criteria}

- Age above 12 months to approximately 24 months

- Attending and taking food and drinks at licensed day care centres

- Malay ethnicity only, to minimise cultural influence on child care behavior and complementary feeding practices 
- Apparently healthy; no symptoms of fever, coughing, and running nose during dietary intake assessment and blood drawing.

\section{Exclusion criteria}

- Having chronic or serious illness

- Under medication or unwell during recruitment

- Parents who refused to provide written consent

\section{Sample size}

It was computed that 150 subjects would be the minimum sample size required to estimate the ganglioside intake within a tolerable error of $10 \mathrm{mg} / 4187 \mathrm{~kJ}(0.16$ SD) with a power of $80 \%$ and a $5 \%$ level of confidence. This calculation is based on the assumption that the SD of dietary ganglioside intake in adults is about $62 \mathrm{mg} /$ $4187 \mathrm{~kJ}$ [24]. A total of 153 subjects were recruited for this study.

In anticipation of the challenges of getting consent from parents and children to provide blood samples, it was decided to draw blood from a sub-group of the total sample of 150. A minimum of 70 subjects was computed to be sufficient to estimate the ganglioside intake within a tolerable error of $0.67 \mathrm{mg} / \mathrm{dl}(0.24 \mathrm{SD})$ with a power of $80 \%$ and a $5 \%$ level of confidence. This calculation was based on the assumption that the standard deviation of the total serum gangliosides is approximately $2.78 \mathrm{mg} /$ $100 \mathrm{ml}$ [25]. The above sample size of 70 was also sufficient to detect a moderate correlation of 0.3 between dietary intake of gangliosides and serum ganglioside status at a $5 \%$ level of confidence and a power of $80 \%$.

Data collection - background of all participants $(N=153)$ Mothers/care givers of the participants were interviewed using a pre-tested structured questionnaire. Questions pertaining to the socio-economic background of the parents, breast feeding practice and age at introduction of complementary foods were included in the questionnaire.

\section{Dietary intake of participants $(N=153)$ using Food Frequency Questionnaire (FFQ)}

A food frequency questionnaire (FFQ) was used to obtain information on the types and frequency of foods commonly consumed by the entire group of participants. The FFQ data is important to provide information on overall food sources of gangliosides in the toddlers' diets. The FFQ data supports the weighed records of dietary intake, which is limited to only 2 days' intake and for a sub-group of the participants.

The questionnaire was pre-tested on five parents from a similar background as the recruited participants. They were conveniently selected to test if the FFQ had any technical or ambiguous terms that parents could not understand. After making the necessary amendments, the FFQ was posed to parents/guardians of all the participants $(N=153)$. The FFQ comprised a list of specific food items and the response options for each food ranged from "not at all", "1-3 times a day", "4-6 times a day", "1-3 times a week" to "4-6 times a week". Parents/ care givers were interviewed on the frequency intake of each of the foods and beverages consumed by their child during the past one week prior to the interview.

\section{2-day weighed food record of sub-group of participants $(N=74)$}

In order to gather detailed information on actual amounts of specific foods and beverages consumed by the participants who provided blood for ganglioside correlation determination, a 2-day weighed food record was obtained for a sub-group of the participants $(N=74)$. Weighing of the meals taken in the centres was carried out by research assistants who were nutrition/dietetics graduates trained in dietary intake assessment. Duplicate plates of the meal were prepared and individual items were weighed using a kitchen scale with weight capacity of $2.0 \mathrm{~kg}$ and weight graduation of $1.0 \mathrm{~g}$ (TANITAKD160WH). The amounts not consumed or spilled were deducted from the total amounts weighed. The research assistants checked for ingredients used in preparing the food items by asking the person who prepared the foods.

As for foods and beverages consumed at home during the 2-day food weighing period, mothers/care givers were instructed on how to record the types and amounts of food and beverages consumed by their participating child. The research assistants checked for incomplete information when the mothers/care givers returned the forms.

Determination of gangliosides in foods consumed by subgroup $(N=74)$

For the ganglioside correlation analysis, samples of foods and beverages of animal origin, that were consumed by the participants during the 2-days weighing of food intake in the centres, were purchased from supermarkets and grocery stores. Foods of plant origin were not included as they are not known to have ganglioside content [7]. The same or equivalent brand, type and flavour of milk powder, dairy products (e.g. yoghurt and cheese), bread and biscuits were purchased as those consumed by the participants. Fish and fish balls were purchased as close to the types consumed.

Approximately $100-150 \mathrm{~g}$ of each sample was packed, labelled and frozen prior to being air-freighted to New Zealand for determination of ganglioside contents. Some products such as meat and dairy products (the equivalent dairy product or product brand) were purchased in supermarkets in Palmerston North, New Zealand. Only 
one item of each food was purchased for ganglioside analysis.

In Palmerston North, all meat and fish samples were cut into samples $(20 \mathrm{~g})$ and freeze dried. The freeze dried samples were milled into a powder using a domestic coffee grinder. Dry foods such as biscuits and cake were milled without freeze drying. Approximately 0.1 to $0.2 \mathrm{~g}$ of freeze dried powder or dry sample was weighed into Kimax tubes $(10 \mathrm{~mL})$ together with water $(0.4 \mathrm{~mL})$. Samples were mixed and allowed to rehydrate for 10 min prior to lipid extraction. Liquid samples $(0.5 \mathrm{~mL})$ were extracted directly. Samples such as egg yolk and milk powder were made up as a $10 \%$ solution in water. An aliquot $(0.5 \mathrm{~mL})$ of these rehydrated was used for analysis. All samples were extracted for lipids as described in [26].

The extracted samples were analyzed for gangliosides using high performance liquid chromatography-mass spectrometry (HPLC-MS) [26]. Briefly, the HPLC analysis was performed on an Agilent 1100 series HPLC system (Santa Clara, CA) consisting of a quaternary pump, binary pump, degasser, column heater $\left(60{ }^{\circ} \mathrm{C}\right)$, and refrigerated auto-sampler $\left(5^{\circ} \mathrm{C}\right)$. Samples or standards $(5 \mu \mathrm{L})$ were initially loaded $(0.5 \mathrm{~mL} / \mathrm{min} ; 50 \%$ methanol $)$ on to a wide pore, reversed-phase trap $(\mathrm{C} 18,4 \mathrm{~mm} \times 2.0 \mathrm{~mm}, 5 \mu \mathrm{m}$, Phenomenex, CA) for preconcentration/desalting. After 8 min, the trap was switched in-line with an APS-2 Hypersil hydrophilic column $(150 \mathrm{~mm} \times 2.1 \mathrm{~mm}, 3 \mu \mathrm{m}$, Thermo Electron Corporation, Waltham, MA) coupled to an APS2 guard column $(10 \mathrm{~mm} \times 2.1 \mathrm{~mm}$ inner diameter). The gangliosides were separated with an acetonitrile:ammonium acetate buffer gradient with the eluate from the HPLC system introduced into an LTQ-Orbitrap ${ }^{\text {Tw }}$ mass spectrometer (Thermo Electron Corporation, Waltham, MA) using an ESI probe inlet. The resolving power of the LTQ-Orbitrap $^{\text {tw }}$ mass spectrometer was used to filter post analysis for known masses of ganglioside species present within each class of ganglioside measured.

Based on the ganglioside contents determined in the food items, the actual amounts of gangliosides consumed by the subjects were computed using the 2-day weighed food records.

\section{Blood samples drawn from sub-group $(N=74)$}

Non-fasting blood was collected from a total of 74 participants for determination of serum ganglioside concentrations. It would have been very challenging to collect fasting blood from the young participants, with almost half of them still being breastfed; moreover, for the convenience of parents, drawing of blood could only be scheduled after 9 am.

Blood samples of approximately $2 \mathrm{~mL}$ each were collected from a total of 74 subjects with parental consent. The blood sample was placed in a tube containing silica that acts as clot activator and a polymer gel as a barrier to separate serum from red blood cells. The blood samples were spun to separate out the red cells and the serum samples were stored at minus $80{ }^{\circ} \mathrm{C}$ in International Medical University (IMU), until ready to be air freighted to Palmerston North, New Zealand for ganglioside determination.

\section{Determination of plasma gangliosides concentrations of sub-group $(N=74)$ \\ Blood serum samples $(0.5 \mathrm{~mL})$ were extracted for gangli- osides using the same protocol as described for foods. The final extract was made up to $5 \mathrm{~mL}$ in $50 \%$ methanol. The extracted samples were analysed for gangliosides using high performance liquid chromatography-mass spectrometry (HPLC-MS) as described in [26].}

\section{Statistical data analysis}

Data analysis was conducted using SPSS (SPSS for Windows, version 20.0) for descriptive and inferential statistics. Pearson's correlation was used to test the relationship between dietary sources of gangliosides and serum ganglioside concentrations. A $p$-value of $<0.05$ was considered statistically significant.

\section{Results}

\section{Background of subjects}

A total of 153 toddlers who met the desired criteria were included in the study. They comprised an almost equal proportion of male (51.6\%) and female subjects (48.4\%), with an average age of $18.8 \pm 0.3$ months (Table 1). While three-quarters of the subjects had normal body mass index for age (BMI-for-age), $12.4 \%$ and $5.9 \%$ were at risk of overweight and overweight, respectively [27].

The fathers and mothers of the subjects were $34.1 \pm$ 0.4 years and $32.8 \pm 0.3$ years of age, respectively. About half of the fathers and mothers had university education qualifications. More than half of the fathers and mothers had monthly income of between RM3000 and RM6000 ${ }^{2}$ Overall, the subjects were from families with socioeconomic status that placed them above the median household monthly income of RM5156 for urban households in Malaysia in 2014 [28].

All the subjects were breastfed at birth, and about half (47.7\%) were still consuming breast milk during the study. Among those no longer taking breast milk, almost half $(46.2 \%)$ had stopped when they were less than 6 months of age (Table 2). Infant formula was the most popular type of complementary food introduced in the first 6 months of age (65.4\%) followed by commercial cereals $(58.1 \%)$ and rice porridge $(42.5 \%)$. 
Table 1 Background characteristics of subjects and parents for $N=153$ and $N=74$

\begin{tabular}{|c|c|c|c|c|}
\hline \multirow[t]{2}{*}{ Characteristics } & \multicolumn{2}{|c|}{ Entire group $(N=153)$} & \multicolumn{2}{|c|}{ Sub group $(N=74)$} \\
\hline & n (\%) & Mean \pm SE & n (\%) & Mean \pm SE \\
\hline \multicolumn{5}{|l|}{ SUBJECT } \\
\hline Age (months) & & $18.8 \pm 0.3$ & & $18.7 \pm 0.4$ \\
\hline $12.0-17.9$ & $61(39.9)$ & & $29(39.2)$ & \\
\hline $18.0-24.5$ & $92(60.1$ & & $45(60.8)$ & \\
\hline BMI-for-age $^{a}$ & & $0.06 \pm 0.09$ & & $0.00 \pm 0.13$ \\
\hline Moderately thin & $5(3.3)$ & & $2(2.7)$ & \\
\hline Normal & $120(78.4)$ & & $57(77.0)$ & \\
\hline At risk of overweight & 19 (12.4) & & $10(13.5)$ & \\
\hline Overweight & $9(5.9)$ & & $5(6.8)$ & \\
\hline \multicolumn{5}{|l|}{ FATHER } \\
\hline Age (years) & & $34.1 \pm 0.4$ & & $33.6 \pm 0.5$ \\
\hline \multicolumn{5}{|l|}{ Education level completed } \\
\hline Secondary school & $24(15.7)$ & & $13(17.6)$ & \\
\hline Matriculation/Diploma & $58(37.9)$ & & $31(41.9)$ & \\
\hline Degree & $71(46.4)$ & & $30(40.5)$ & \\
\hline \multicolumn{5}{|l|}{ Monthly income $(\mathrm{RM})^{\mathrm{b}}$} \\
\hline Less than 3000 & $47(30.7)$ & & $23(31.0)$ & \\
\hline $3000-6000$ & $89(58.2)$ & & $44(59.5)$ & \\
\hline More than 6000 & $17(11.1)$ & & $7(9.5)$ & \\
\hline \multicolumn{5}{|l|}{ MOTHER } \\
\hline Age (years) & & $32.8 \pm 0.3$ & & $32.2 \pm 0.4$ \\
\hline \multicolumn{5}{|l|}{ Education level } \\
\hline Secondary school & $12(7.8)$ & & $5(6.8)$ & \\
\hline Matriculation/Diploma & $60(39.3)$ & & $26(35.1)$ & \\
\hline Degree & $81(52.9)$ & & $43(58.1)$ & \\
\hline \multicolumn{5}{|l|}{ Monthly income (RM) ${ }^{b}$} \\
\hline Less than 3000 & $53(34.6)$ & & $26(35.1)$ & \\
\hline $3000-6000$ & $92(60.1)$ & & $44(59.5)$ & \\
\hline More than 6000 & $8(5.3)$ & & $4(5.4)$ & \\
\hline
\end{tabular}

${ }^{\mathrm{a}}$ Body mass index-for-age $z$ score: Moderately thin (BMI-for-age $z$ score $<-2.0$ SD to -3.0 SD); Normal (BMI-for-age $z$ score $\geq-2.0$ SD to $<+1$ SD); At risk of overweight (BMI-for-age $z$ score $\geq+1$ SD to $<+2.0$ SD); Overweight (BMI-for-age $z$ score $\geq+2.0$ SD) [27]; ${ }^{\text {b }} \sim$ RM4 to US1.00

\section{Dietary intake of entire group based on FFQ Cereal-based foods}

Rice porridge is a common complementary food in Malaysia. Rice porridge with chicken or fish was taken by $73.2 \%$ and $63.4 \%$ of the subjects at least once a week, respectively. Bread with spread (usually margarine, jam or peanut butter) was consumed by $43.8 \%$ on a weekly basis. About 26.1\% consumed biscuits at least once a day. Spaghetti was eaten with either meat or sausage at least $1-3$ times a week by $35.9 \%$ and $20.3 \%$, respectively.

\section{Meat, fish and eggs}

Relatively high proportions of the subjects consumed chicken meat (79.8\%), chicken nuggets (55.0\%), and beef
(41.2\%) at least 1-3 times a week. Fish was popular being taken by $83.7 \%$ at least $1-3$ times a week. Eggs were also popular with fried egg consumed by $61.8 \%$ at least 1-3 times a week, and boiled egg consumed by $44.5 \%$ at least once a week.

Milk and dairy products (including growing up milks)

As mentioned previously, nearly half of the subjects were breastfed $(47.7 \%)$ at the time of the study. Among these subjects, $68.5 \%$ were breastfed more than 3 times a day. The majority of the subjects $(73.2 \%)$ was consuming growing up milk, including those who were breastfed. Out of these, most were taking growing up milk more than 3 times a day (69.6\%), while $25.6 \%$ had growing 
Table 2 Breastfeeding and complementary feeding practices for $N=153$ and $N=74$

\begin{tabular}{|c|c|c|}
\hline Participating child & $\begin{array}{l}\text { Entire group }(N=153) \\
\text { n }(\%)\end{array}$ & $\begin{array}{l}\text { Sub group }(N=74) \\
\mathrm{n}(\%)\end{array}$ \\
\hline \multicolumn{3}{|c|}{ Has child ever been breastfed? } \\
\hline Yes & $153(100)$ & $74(100)$ \\
\hline \multicolumn{3}{|l|}{ Still breastfed? } \\
\hline Yes & $73(47.7)$ & $35(47.3)$ \\
\hline No & $80(52.3)$ & $39(52.7)$ \\
\hline \multicolumn{3}{|c|}{ If no longer breastfed, child's age when breastfeeding ceased? } \\
\hline Before 1 month & $2(2.4)$ & $1(2.6)$ \\
\hline $1-3$ months & $12(15.0)$ & $8(20.5)$ \\
\hline $3-6$ months & $23(28.8)$ & $13(33.3)$ \\
\hline After 6 months & $43(53.8)$ & $17(43.6)$ \\
\hline \multicolumn{3}{|c|}{ Proportions receiving growing up milk } \\
\hline 12.0-17.9 months & $46(75.4)$ & $21(72.4)$ \\
\hline 18.0-24.5 months & $79(85.9)$ & $36(80.0)$ \\
\hline \multicolumn{3}{|c|}{ Child's age when first solid/semi-solid foods given? } \\
\hline Before 3 months & $7(4.6)$ & $5(6.8)$ \\
\hline $3-5$ months & $18(11.8)$ & $10(13.5)$ \\
\hline At 6 months & 79 (51.6) & $35(47.3)$ \\
\hline After 6 months & $49(32.0)$ & $24(32.4)$ \\
\hline \multicolumn{3}{|c|}{ aType of food introduced in the first 6 months? } \\
\hline Infant formula & $100(65.4)$ & $53(71.6)$ \\
\hline Commercial cereals & $89(58.1)$ & $41(55.4)$ \\
\hline Rice porridge & $65(42.5)$ & $32(43.2)$ \\
\hline Fruit puree & $49(32.0)$ & $21(28.4)$ \\
\hline Vegetable puree & $39(25.5)$ & $17(23.0)$ \\
\hline
\end{tabular}

${ }^{a}$ mothers reported introducing more than one type of food

up milk 1-3 times a day. Yoghurt and yoghurt drinks were quite popular being consumed by more than half of the subjects (52.3\%) at least 1-3 times a week. About 35.9\% reported taking cheese at least once a week.

\section{Dietary intake of sub-group based on 2-day weighed food records}

As described in the Methods, the dietary intake of a subgroup of 74 was assessed by weighing all foods and beverages consumed over two days. Based on the weighed food records, the amounts of calories and nutrients consumed per day were computed. The daily amounts of calories and nutrients consumed were in turn converted to percentages of meeting the Malaysian recommended daily nutrient intake (RNI) [29].

On average, the intake of calories, protein, iron, thiamin and riboflavin per day exceeded the respective recommended daily intake levels $(>100 \%$ RNI). Frequent consumption of animal food sources including meat, fish, eggs and milk were likely the main sources of these nutrients.

The mean daily intake of vitamin $\mathrm{C}$, vitamin $\mathrm{A}$, niacin and vitamin $\mathrm{E}$ were comparatively lower, meeting between 70 and $100 \%$ of the respective RNI levels. This finding could be attributed to inadequate consumption of fruits and vegetables. Introduction to these foods in the first 6 months of age was low, at 32.2\% and 25.5\% for fruits and vegetables, respectively (Table 2).

Meanwhile, the mean intake of calcium and vitamin D met less than $60 \%$ of their respective RNI levels. It is likely the subjects were not getting sufficient quantities of these nutrients from food sources, despite reportedly consuming quite frequently dairy products rich in calcium and vitamin $\mathrm{D}$.

Among the micronutrients, folate intake was the lowest in achieving less than $40 \%$ of its RNI level, on average. Poor intake of folate could be attributed to low consumption of dietary sources of folate, including legumes and dark green vegetables.

Overall, the dietary intake results indicate adequate consumption of calories, protein and several essential micronutrients among the subjects. Caution should be exercised when interpreting self-reporting dietary intake data. In this study, parents reported their child's intake, and shortcomings may arise due to errors in recall memory, and lack of familiarity with food ingredients leading to misreporting.

\section{Dietary intake of gangliosides of sub-group}

Overall, the subjects consumed an average daily amount of $5.86 \pm 0.56 \mathrm{mg}$ (mean $\pm \mathrm{SE}$ ) of total gangliosides. Table 3 shows the mean ganglioside intake from each of five major food categories. Cow's milk especially growing up milk was the major source of gangliosides contributing $5.05 \pm 0.56 \mathrm{mg}$ or about $85 \%$ of total gangliosides consumed. Smaller quantities of gangliosides were derived from other food categories namely, meat/chicken

Table 3 Mean dietary intake of gangliosides $(N=74)^{*}$, **

\begin{tabular}{lll}
\hline & \multicolumn{2}{l}{ a Ganglioside intake $(\mathrm{mg})$ per day } \\
\cline { 2 - 3 } Food sources & Mean \pm SE & Median, $25^{\text {th }}$ and $75^{\text {th }}$ percentile \\
\hline Growing up milk & $5.05 \pm 0.56$ & $6.22,3.23,11.46$ \\
Meat $^{\mathrm{a}}$ & $0.35 \pm 0.04$ & $0.29,0.18,0.45$ \\
Fish $^{\text {Dairy products }}{ }^{\mathrm{b}}$ & $0.18 \pm 0.03$ & $0.01,0.0,0.21$ \\
Bakery/Biscuits & $0.15 \pm 0.06$ & $0.00,0.00,0.05$ \\
All food sources & $5.86 \pm 0.03$ & $0.05,0.01,0.15$ \\
\hline
\end{tabular}

${ }^{*}$ Compilation based on ganglioside concentrations of food items determined by Fonterra Research and Development Centre, NZ

** Mean ganglioside intake per day (mg), based on 2 days weighed food records

${ }^{a}$ Meat: chicken meat, beef, eggs

${ }^{b}$ Dairy products: yoghurt, ice cream, cheese 
liver/egg yolk $(0.35 \pm 0.04 \mathrm{mg})$, fish $(0.18 \pm 0.03 \mathrm{mg})$, dairy products $(0.15 \pm 0.06 \mathrm{mg})$ and bakery/cakes/biscuits $(0.13 \pm 0.03 \mathrm{mg})$. Meat consumed was mostly chicken and to a lesser extent beef, while dairy products were mainly yoghurt, ice-cream and cheese.
A total of 39 different types of bovine and goat growing up milk were consumed by the subjects (Table 4). The mean total gangliosides of these milk products varied widely ranging from 0.03 to $11.0 \mathrm{mg} / 100 \mathrm{~g}$, with goat milk having the lowest ganglioside levels. The dominant

Table 4 Total ganglioside concentrations (mg/100 g) of growing up milk powders consumed by subjects $(N=74)$

\begin{tabular}{|c|c|c|c|c|}
\hline Sample Number & Base powder & GM3 & GD3 & Total ganglioside \\
\hline 1 & Goat milk & 0.0 & 0.0 & 0.03 \\
\hline 2 & Goat milk - Chocolate & 0.0 & 0.1 & 0.1 \\
\hline 3 & Goat milk & 0.0 & 0.1 & 0.1 \\
\hline 4 & Goat milk & 0.0 & 0.2 & 0.2 \\
\hline 5 & Goat milk & 0.0 & 0.2 & 0.2 \\
\hline 6 & Goat milk & 0.0 & 0.2 & 0.2 \\
\hline 7 & Bovine milk - Honey & 0.0 & 0.5 & 0.5 \\
\hline 8 & Bovine milk & 0.0 & 0.5 & 0.5 \\
\hline 9 & Bovine milk - Fruit \& vegetable & 0.0 & 0.6 & 0.6 \\
\hline 10 & Bovine milk & 0.0 & 1.6 & 1.6 \\
\hline 11 & Bovine milk & 0.0 & 2.3 & 2.3 \\
\hline 12 & Bovine milk - Vanilla & 0.0 & 2.9 & 2.9 \\
\hline 13 & Bovine milk - Chocolate & 0.0 & 3.1 & 3.1 \\
\hline 14 & Bovine milk & 0.0 & 3.2 & 3.2 \\
\hline 15 & Bovine milk - Vanilla & 0.0 & 3.6 & 3.6 \\
\hline 16 & Bovine milk & 0.0 & 3.7 & 3.7 \\
\hline 17 & Bovine milk & 0.0 & 3.7 & 3.7 \\
\hline 18 & Bovine milk & 0.0 & 3.7 & 3.7 \\
\hline 19 & Bovine milk (Full cream) & 0.0 & 3.9 & 3.9 \\
\hline 20 & Bovine milk & 0.0 & 4.4 & 4.4 \\
\hline 21 & Bovine milk - Chocolate & 0.0 & 4.4 & 4.4 \\
\hline 22 & Bovine milk & 0.0 & 4.9 & 4.9 \\
\hline 23 & Bovine milk & 0.0 & 5.0 & 5.0 \\
\hline 24 & Bovine milk & 0.0 & 5.0 & 5.0 \\
\hline 25 & Bovine milk & 0.0 & 5.2 & 5.2 \\
\hline 26 & Bovine milk & 0.0 & 5.2 & 5.2 \\
\hline 27 & Bovine milk & 0.0 & 5.8 & 5.8 \\
\hline 28 & Bovine milk & 0.0 & 6.0 & 6.0 \\
\hline 29 & Bovine milk & 0.0 & 6.2 & 6.2 \\
\hline 30 & Bovine milk & 0.0 & 6.9 & 6.9 \\
\hline 31 & Bovine milk & 0.0 & 7.1 & 7.1 \\
\hline 32 & Bovine milk & 0.0 & 7.2 & 7.2 \\
\hline 33 & Bovine milk & 0.0 & 7.6 & 7.6 \\
\hline 34 & Bovine milk & 0.0 & 8.5 & 8.5 \\
\hline 35 & Bovine milk & 0.0 & 8.8 & 8.8 \\
\hline 36 & Bovine milk & 0.0 & 9.4 & 9.4 \\
\hline 37 & Bovine milk & 0.0 & 10.6 & 10.6 \\
\hline 38 & Bovine milk & 0.1 & 10.9 & 11.0 \\
\hline 39 & Bovine milk & 0.0 & 11.4 & 11.4 \\
\hline
\end{tabular}


ganglioside class in these growing up milk products is GD3.

Besides growing up milk, the total ganglioside contents of the other food categories were also determined (Table 5). Chicken liver has the highest ganglioside content on a $100 \mathrm{~g}$ basis $(29 \mathrm{mg})$ followed by chicken egg yolk ( $15.9 \mathrm{mg} / 100 \mathrm{~g})$ and duck egg yolk $(5.0 \mathrm{mg} / 100 \mathrm{~g})$. Meat has relatively lower total gangliosides, e.g. chicken $(0.4-1.5 \mathrm{mg} / 100 \mathrm{~g})$ and beef $(0.3-0.9 \mathrm{mg} / 100 \mathrm{~g})$. This compares with $11.2 \mathrm{~g} / 100 \mathrm{~g}$ for whole milk powder, $8.8 \mathrm{mg} / 100 \mathrm{~g}$ for skim milk powder, $1.37-1.62 \mathrm{mg} / 100 \mathrm{~mL}$ for liquid milks and $0.69-0.84 \mathrm{mg} /$ $100 \mathrm{~g}$ for yoghurt (Table 4).

In fish, total ganglioside contents also varied widely according to the species, and some commonly available fish in the Malaysian market place have comparatively high ganglioside contents, including anchovies $(9.85 \mathrm{mg} / 100 \mathrm{~g})$, mackerel $(6.09 \mathrm{mg} / 100 \mathrm{~g})$ and threadfin $(4.47 \mathrm{mg} / 100 \mathrm{~g})$ (Table 6). Other sea foods like prawn, crab meat and squids have low amounts of gangliosides.

The subjects consumed a variety of snacks, biscuits, cakes and beverages. The ganglioside contents of these foods were also determined (see Additional file 1). With the exception of milk and milk-products, the snacks generally have low ganglioside contents.

Of the 74 toddlers that had their serum gangliosides determined, half of them were still breast feeding. Unfortunately, dietary ganglioside contribution from breast milk could not be determined as breast milk samples were not collected for this study.

\section{Serum ganglioside concentrations of sub-group}

Total serum ganglioside concentrations of the subjects varied widely, from $5.05 \mu \mathrm{g} / \mathrm{mL}$ to $16.15 \mu \mathrm{g} / \mathrm{mL}$, with a mean value of $9.70 \pm 2 \mu \mathrm{g} / \mathrm{mL}$. The major serum ganglioside class determined in the subjects was GM3 with a mean concentration of $7.96 \pm 2.20 \mu \mathrm{g} / \mathrm{mL}$, making up $73-89 \%$ of total serum gangliosides (Table 7) (refer to the Abbreviations for ganglioside class nomenclature). GM3 is the principal ganglioside class found in fish, chicken liver and egg yolks. The other ganglioside classes identified in the serum were gangliosides GD3 and GD1a. Cow's milk is the major source of ganglioside GD3 (milk powder, whole milk, condensed milk) followed by dairy products (e.g. cheese, butter, ice cream) and bakery products (pancakes, biscuits, cakes) (Additional file 1). Mature human breast milk contains a mix of GD3 and GM3 [7].

\section{Correlations between dietary intake gangliosides and serum ganglioside concentrations}

Consumption of gangliosides from different food categories was examined for correlations with plasma total gangliosides and serum GM3, GD3 and GD1a. Although the consumption of certain foods, such as meat and dairy products showed a significant correlation with total serum gangliosides, the correlation was not strong (correlation coefficients of 0.298 and 0.241, respectively) (Table 8). Meat intake also showed a significant but weak correlation with each of the individual serum ganglioside classes. Similarly, consumption

Table 5 Total ganglioside concentrations (mg/100 g) of meat/liver/egg consumed by subjects $(N=74)$

\begin{tabular}{|c|c|c|c|c|c|}
\hline \multirow[t]{3}{*}{ Liver, Meat, Egg } & \multicolumn{4}{|c|}{$\mathrm{mg} / 100 \mathrm{gm}$} & \multirow[t]{3}{*}{ Total gangliosides } \\
\hline & \multicolumn{4}{|c|}{ Ganglioside class } & \\
\hline & $\overline{\text { GD1a }}$ & GM4 & GM3 & GD3 & \\
\hline Bovine liver & 5.1 & 0.0 & 0.7 & 0.2 & 5.9 \\
\hline Chicken liver & 0.9 & 1.7 & 26.8 & 0.6 & 29.0 \\
\hline Chicken thigh (with skin) & 0 & 0.0 & 1.1 & 0.3 & 1.4 \\
\hline Chicken breast (with skin) & 0 & 0.0 & 0.7 & 0.2 & 0.9 \\
\hline Chicken Nugget & 0 & 0.0 & 1.4 & 0.1 & 1.5 \\
\hline Beef blade steak & 0 & 0.0 & 0.8 & 0.1 & 0.9 \\
\hline Prime minced beef meat & 0 & 0.0 & 0.5 & 0.0 & 0.5 \\
\hline Pork Mince meat & 0 & 0.0 & 0.3 & 0.0 & 0.3 \\
\hline Chicken whole egg (free range) & 0 & 1.0 & 0.1 & 0.0 & 1.1 \\
\hline Chicken egg yolk (free range) & 0 & 3.3 & 12.0 & 0.6 & 15.9 \\
\hline Caged whole egg & 0 & 0.5 & 0.9 & 0.1 & 1.5 \\
\hline Cage egg yolk & 0 & 3.4 & 3.3 & 0.3 & 7.0 \\
\hline duck egg 1 (whole -free range) & 0 & 0.7 & 0.0 & 0.0 & 0.8 \\
\hline duck egg 2 (whole -free range) & 0 & 0.6 & 0.0 & 0.0 & 0.6 \\
\hline Duck egg yolk -free range & 0 & 1.9 & 2.7 & 0.5 & 5.0 \\
\hline Duck egg yolk -free range & 0 & 1.5 & 2.5 & 0.4 & 4.4 \\
\hline
\end{tabular}


Table 6 Total ganglioside concentrations $(\mathrm{mg} / 100 \mathrm{~g})$ of fish/sea foods consumed by subjects $(\mathrm{N}=74)$

\begin{tabular}{|c|c|c|c|c|c|c|}
\hline \multirow[t]{2}{*}{ Fish, crab meat, prawn/squid } & \multicolumn{5}{|c|}{$\mathrm{mg} / 100 \mathrm{~g}$ product } & \multirow[t]{2}{*}{ Total gangliosides } \\
\hline & GD1a & GD1b & GM2 & GM3 & $\overline{\mathrm{GD} 3}$ & \\
\hline "Ikan Cencaru"; Hardtail scad (Megalaspis cordyla) & 0.00 & 0.00 & 0.00 & 1.72 & 0.01 & 1.73 \\
\hline "Ikan Bawal"; Silver pomfret (Pampus argenteus) & 0.00 & 0.00 & 0.00 & 0.92 & 0.03 & 0.95 \\
\hline "lkan Siakap"; Giant sea perch, (Barramundi Lates Calcarifer) & 0.00 & 0.00 & 0.00 & 0.60 & 0.03 & 0.62 \\
\hline "Ikan Kembung"; Faughni Mackerel, Island Mackerel; (Rastrelliger faughni Matsui) & 0.38 & 0.01 & 0.24 & 5.86 & 0.23 & 6.48 \\
\hline "Ikan Tenggiri"; Streaked seerfish (Scomberomorus) & 0.00 & 0.00 & 0.00 & 0.87 & 0.00 & 0.88 \\
\hline Dory fish & & & & 0.77 & 0.01 & 0.78 \\
\hline Sardine (Sardina pilchardus) & 0.00 & 0.00 & 0.00 & 2.48 & 0.01 & 2.48 \\
\hline "Ikan Selar"; Yellow tail scad; (Atule mate) & & & & 0.87 & 0.01 & 0.87 \\
\hline "Ikan Keli"; cat fish; (Siluriformes) & 0.00 & 0.00 & 0.00 & 1.47 & 0.03 & 1.49 \\
\hline "Ikan Putih"; "Bawal Putih" (Puntius binotatus) & 0.00 & 0.00 & 0.00 & 0.10 & 0.01 & 0.10 \\
\hline "kan Senangin"; East Asian fourfinger threadfin; (Eleutheronema tetradactylum) & 0.00 & 0.00 & 0.00 & 4.45 & 0.02 & 4.47 \\
\hline "kan Talapia", Mozambique Tilapia (Oreochromis mossambicus) & 0.00 & 0.00 & 0.00 & 0.01 & 0.00 & 0.01 \\
\hline "Ikan bilis"; dried Indian Anchovies; (Stolephorus indicus) & 0.00 & 0.00 & 0.00 & 9.80 & 0.05 & 9.85 \\
\hline "Keropok" fish crackers & 0.00 & 0.00 & 0.00 & 1.12 & 0.01 & 1.13 \\
\hline "Muruku ikan" fish crackers & 0.00 & 0.00 & 0.00 & 0.25 & 0.00 & 0.25 \\
\hline fishball & 0.00 & 0.00 & 0.00 & 0.23 & 0.00 & 0.23 \\
\hline Fish cake & 0.00 & 0.00 & 0.00 & 0.03 & 0.00 & 0.03 \\
\hline Tuna yellow fin -meat only & 0.00 & 0.00 & 0.00 & 0.20 & 0.01 & 0.22 \\
\hline Snapper (NZ) - meat only (Chrysophrys auratus) & 0.01 & 0.03 & 0.00 & 0.7 & 0.02 & 0.76 \\
\hline Crab meat frozen & 0.00 & 0.00 & 0.00 & 0.44 & 0.06 & 0.50 \\
\hline frozen squid tube & 0.00 & 0.00 & 0.00 & 0.74 & 0.02 & 0.75 \\
\hline Littleneck clams (NZ) (Austrovenus stutchburi) & 0.00 & 0.00 & 0.00 & 0.35 & 0.01 & 0.36 \\
\hline Imported frozen Vanemaei Prawn & 0.00 & 0.00 & 0.00 & 0.01 & 0.01 & 0.02 \\
\hline Salmon (NZ) farmed & 0.00 & 0.00 & 0.00 & 0.98 & 0.11 & 1.04 \\
\hline
\end{tabular}

Name in Malay language: ${ }^{m \prime}$

Scientific name: ()

of bakery products/biscuits showed a significant, but weak correlation with serum GD3 and GD1a concentration.

No significant correlation was observed for fish, despite it contributing similar dietary ganglioside levels as dairy products and bakery. Similarly, there was no significant correlation between dietary gangliosides from growing up milk and serum ganglioside (total or individual gangliosides), despite growing up milk being the major contributor of dietary gangliosides for the toddlers.

Table 7 Serum ganglioside concentrations (total and by class) of subjects $(N=74)$

\begin{tabular}{lc}
\hline Ganglioside class & $\begin{array}{l}\text { Serum ganglioside } \\
\text { concentration }(\mathrm{ug} / \mathrm{mL}) \\
\text { Mean } \pm \mathrm{SD}\end{array}$ \\
\hline GM3 & $7.96 \pm 2.20$ \\
GD3 & $1.27 \pm 0.36$ \\
GD1a & $0.46 \pm 0.16$ \\
All ganglioside classes & $9.70 \pm 2.57$ \\
\hline
\end{tabular}

\section{Discussion}

To the best of our knowledge, this is likely the first study to determine ganglioside consumption and its relationship with serum ganglioside status among toddlers. In a sample of urban Malay toddlers aged 12.0-24.5 months, their primary food source of gangliosides was bovine milk. Much lower quantities of ganglioside were derived from other dietary sources such as chicken, liver, egg yolk and fish. A few studies have reported low intake levels of ganglioside in normal healthy population groups. Among adults in Edmonton, Canada, Pham et al. [24] estimated low levels of ganglioside intake, (measured as LBSA), mainly from egg yolk and cooked ground beef followed by canned tuna, yogurt, cheddar cheese, and milk. Vesper et al. [30] estimated the daily intake of sphingolipids in the general population of United States as $0.3-0.4 \mathrm{~g} /$ day. Gangliosides constitute only a small percentage of sphingolipid intake [7]. According to Miklavcic et al. [31], dietary ganglioside intake is normally very low, unless whole organ foods, whole milk, buttermilk, or colostrum are consumed in high quantities. 
Table 8 Correlations* between mean ganglioside** intake from different dietary sources and serum ganglioside concentrations (total and classes) $(N=74)$

\begin{tabular}{|c|c|c|c|c|c|c|c|c|}
\hline \multirow[t]{3}{*}{ Food sources } & \multicolumn{8}{|c|}{ Serum ganglioside } \\
\hline & \multicolumn{2}{|l|}{ GM3 } & \multicolumn{2}{|l|}{ GD3 } & \multicolumn{2}{|l|}{ GD1a } & \multicolumn{2}{|l|}{ Total } \\
\hline & Corr & $p$ & Corr & $p$ & Corr & $p$ & Corr & $p$ \\
\hline Growing up milk & -0.032 & 0.787 & -0.057 & 0.631 & -0.120 & 0.307 & -0.047 & 0.690 \\
\hline Meat ${ }^{\mathrm{a}}$ & 0.294 & $0.011^{*}$ & 0.230 & $0.049^{*}$ & 0.258 & $0.026^{*}$ & 0.298 & $0.010^{\circ}$ \\
\hline Fish & 0.059 & 0.618 & 0.196 & 0.095 & 0.123 & 0.297 & 0.086 & 0.464 \\
\hline Dairy products ${ }^{b}$ & 0.241 & $0.039^{*}$ & 0.161 & 0.170 & 0.205 & 0.079 & 0.241 & $0.038^{3}$ \\
\hline Bakery/Biscuits & 0.144 & 0.222 & 0.306 & $0.008^{¥}$ & 0.315 & $0.006^{¥}$ & 0.184 & 0.116 \\
\hline All food sources & 0.028 & 0.811 & 0.006 & 0.960 & -0.054 & 0.649 & 0.017 & 0.884 \\
\hline
\end{tabular}

*Pearson correlation

${ }^{* *}$ Mean ganglioside intake per day (mg), based on 2-day weighed food records

${ }^{a}$ Meat: chicken meat, beef, eggs

${ }^{\text {b}}$ Dairy products: yoghurt, ice cream, cheese

${ }^{¥}$ Correlation significant level set at $p<0.05$

In human serum, ganglioside GM3 is evidently the major ganglioside class [32]. About $98 \%$ of serum gangliosides especially in the form of GM3, GD3, GD1a, GM2, GT1b, are transported by serum lipoproteins, predominantly by low-density lipoprotein (LDL) followed by highdensity lipoprotein (HDL) [33].

In the present study, total serum gangliosides were determined between $5.05 \mu \mathrm{g} / \mathrm{mL}$ to $16.15 \mu \mathrm{g} / \mathrm{mL}$, with ganglioside GM3 as the principal class followed by gangliosides GD3 and GD1a at trace levels. Although significant correlations were found between consumption of chicken meat and dairy products and total serum gangliosides, the correlations were weak. Similar observations were also made at an individual ganglioside class level (GM3, GD3 and GD1a), with results being more variable for bakery/biscuit products. These weak correlation findings may be due in part to these food categories (including fish) only contributing to less than $15 \%$ of total dietary gangliosides intake for these toddlers.

Growing up milk contributed to $85 \%$ of the total dietary gangliosides intake for these toddlers, and was expected to have greater impact on the serum ganglioside levels. However, there was a lack of any correlation between dietary ganglioside intakes from these growing milk products with the serum gangliosides levels. The growing up milk correlation data does suggest that perhaps the study was not sensitive enough to pick up any effect, if any, when the dietary gangliosides intake is low. In fact, $90 \%$ of the growing up milk analysed in this study had a ganglioside concentration less than that reported for bovine whole milk powder (9.4-13.7 mg/100 g converted to powder equivalent) $[21,23]$.

The overall, lack of any strong correlation between total dietary ganglioside intake and total serum ganglioside levels could also be attributed to the unavoidable delays between dietary assessment and blood collection. While every attempt was taken to minimize this interval period for each subject, nonetheless, scheduling blood draw was dependent on the convenience of parents to bring their child to the clinic, and to the availability of the attending paediatrician. As the natural diurnal variation in serum gangliosides in this age group is unknown, the varying time intervals encountered may have had an impact on the blood results.

A few feeding trials have shown different time intervals between gangliosides consumption and changes in blood ganglioside levels Indonesian infants aged 2-8 weeks fed with formula milk supplemented with $9 \mathrm{mg}$ GD3/100 g of formula, showed significant changes in serum patterns of several gangliosides after 6-months of supplementation [34]. Another feeding study on Canadian healthy volunteers, who consumed $43 \mathrm{mg}$ /day of gangliosides as a milk fat fraction, showed plasma ganglioside GD3 increased by $35 \%$ after 8 weeks [35].

Blood ganglioside concentrations may well reflect overall ganglioside intake, rather than that of any individual dietary item, particularly in this study setting where intake of gangliosides is generally low, while serum gangliosides levels varied widely among the individuals. According to McJarrow et al. [7], dietary gangliosides produce increased ganglioside levels in the blood and other organs, but what is not well understood is the extent to which "the rise in blood ganglioside is a result of the same gangliosides ingested or whether ganglioside ingested is remodelled in the enterocyte and released into the blood as newly formed ganglioside".

Gurnida et al. [34] found the serum total ganglioside and each individual ganglioside class rose in proportion to each other suggesting a role of the enterocyte in remodelling of the dietary ganglioside which was dominantly GD3. Furthermore blood ganglioside levels can also be influenced by endogenous biosynthesis [7].

In this study, ganglioside contribution from breast milk was not included given the logistics of measuring breast 
milk consumption for toddlers and this could have confounded the correlation analysis. It would be worthwhile for future studies to compare serum ganglioside concentrations between breastfed and non-breastfed subjects, as breast milk is known to contain higher amounts of gangliosides than growing up milk.

\section{Limitations of study}

A major limitation is the omission of gangliosides from breast milk especially since almost half of the participants in the sub-group were still fed breast milk.

Methodological limitations on dietary assessment are expected to affect the quality of weighing of food and FFQ data. It would have been optimal to obtain weighed food intake for 3 days including a weekend. However, weighed intake was undertaken for only 2 days, and this was deemed adequate as the range of foods consumed did not vary much from day to day. The day care centres are closed during weekends and public holidays. The FFQ itself was not validated but based on previous research on toddlers. Another limitation on the use of FFQ is reliance on parents to report foods consumed by their children in the centres. Based on the information provided, parents appeared to be aware of the types of food served in the centres and some parents provided foods from home for their children.

Packaged and fresh food items were purchased in Malaysia and sent to New Zealand for analysis of ganglioside concentrations. Data accuracy of fresh items may be influenced by the convenient sampling manner of purchasing of these items.

As all the participants were from a specific urban area and of Malay ethnicity, the results should not be extrapolated to other ethnic population groups and to other areas in Malaysia.

\section{Conclusion}

Total and specific major classes of gangliosides were identified in the food items consumed by Malaysian toddlers from middle socio-economic status. Growing up milk products were the major contributors to dietary ganglioside intake for these toddlers. Weak correlations were found between dietary ganglioside intakes (for some foods) with serum ganglioside levels of the toddlers. In light of increasing evidence of the potent biological functions of gangliosides in bringing about health benefits for growth, intestinal integrity, and cognitive performance in children, further studies especially human feeding trials are suggested to identify the quantum and types of dietary gangliosides for recommendations in early nutrition.

\section{Nomenclature}

Gangliosides are a class of complex molecules belonging to glycosphingolipids. Their structure is formed by the ceramide core and a sugar chain of several carbohydrate residues, including at least one sialic acid. The nomenclature normally used was first proposed by Svennerholm [36].

GM3: aNeu5Ac(2-3)bDGalp(1-4)bDGlcp(1-1)Cer

GD3: aNeu5Ac(2-8)aNeu5Ac(2-3)bDGalp(1-4)bDGlcp

(1-1)Cer

GD1a: aNeu5Ac(2-3)bDGalp(1-3)bDGalNAc(1-4)[aN eu5Ac(2-3)]bDGalp(1-4)bDGlcp(1-1)Cer

GD1b: bDGalp(1-3)bDGalNAc(1-4)[aNeu5Ac(2-8)aN eu5Ac(2-3)]bDGalp(1-4)bDGlcp(1-1)Cer

Where

aNeu5Ac $=5$-acetyl-alpha-neuraminic acid is the sialic acid

bDGalp = beta-D-galactopyranose

bDGlcp $=$ beta-D-glucopyranose

Cer $=$ ceramide (general $\mathrm{N}$-acylated sphingoid)

bDGalpNAc $=\mathrm{N}$-acetyl-beta-D-galactopyranose

\section{Endnotes}

${ }^{1}$ licensed child care centres are registered with the Social Welfare Department of the Ministry of Women, Family and Community Development and must adhere to government regulations pertaining to care-giver to child ratio, and guidelines on hygiene and food preparation practices.

${ }^{2}$ Approximately RM4.00 equivalent US $\$ 1.00$.

\section{Additional file}

Additional file 1: Total ganglioside concentrations of biscuits/cakes, beverages and dairy products consumed by subjects ( $N=74)$. (DOC $101 \mathrm{~kb})$

\section{Abbreviations}

FFQ: Food frequency questionnaire; HDL: High-density lipoprotein; HPLCMS: High performance liquid chromatography-mass spectrometry;

LBSA: Lipid bound sialic acid; LDL: Low-density lipoprotein;

RNI: Recommended daily nutrient intake; SD: Standard deviation;

WHO: World Health Organization

\section{Acknowledgments}

Gratitude is expressed for the collaboration of the children and parents, as well as the staff of participating day care centres in the Bambino Project. Appreciation also goes to the management and staff of the UPM Health Centre and the IMU Healthcare for permission to use their premises for blood draw. Data analysis by Chua Ee Yin and Lisa Hall is much appreciated. The authors would also like to thank Annie Robinson, Paul McJarrow, Alastair McGibbon and Lin Ma for discussions and reviewing of the manuscript

\section{Funding}

This work was supported by the New Zealand Primary Growth Partnership post-farm gate dairy programme, funded by Fonterra Co-operative Group and the New Zealand Ministry for Primary Industries.

\section{Availability of data and materials}

We are not able to share our data because this is a contract research and the data belongs to the sponsor and International Medical University. Moreover, the researchers intend to publish more articles on this study.

Authors' contributions

GLK, RC and AR conceptualised the study, while GLK, SS, SM and MHHC designed the study and coordinated data collection. NS and YLL contributed to recruitment of subjects and drawing of blood samples. BF was 
responsible for technical analyses of food and blood samples. GLK prepared the draft; GLK and BF edited the final manuscript. All authors read and approved the manuscript.

\section{Authors' information}

GLK is Emeritus Professor of Universiti Putra Malaysia (UPM) and Adjunct Professor of International Medical University, Malaysia (IMU).

SM is Head of Nutrition and Dietetics Division, IMU.

SS and MHZC are lecturers in Nutrition and Dietetics Division, IMU.

NS is a lecturer in Faculty of Medicine and Health Sciences, UPM.

YLL is a paediatrician and lecturer in Faculty of Medicine and Health Sciences, UPM.

$\mathrm{BF}$ is a Senior Scientist at the Fonterra Research and Development Centre. $\mathrm{RC}$ is the Health and Nutrition Lead (Paediatric), Research and Development, Fonterra.

AR is General Manager Nutrition, Research and Development, Fonterra.

\section{Competing interests}

The authors declare that they have no competing interest. The views expressed in the article are solely those of the authors and do not reflect the views of their respective institutions. Fonterra Co-operative Group is a commercial dairy company.

\section{Consent for publication}

As part of the explanation of the Study Information Sheet to the parents, we made clear our research was a scientific study and results would be shown as average values for the entire group of children, and not that of any individual child. The parents were also informed that names of parents and their children will not be revealed in any presentations or publications derived from this study. The Written Consent Form was signed by one of the parents only after all this information had been disclosed to them.

\section{Ethics approval and consent to participate}

The study proposal was approved by the Joint Committee on Research and Ethics of the International Medical University, Kuala Lumpur, Malaysia on 23 July 2014. (Project ID No. IMU R 139/2014). The Study Information Sheet and Written Consent Form in Malay and English were also approved by the IMU Ethics Committee. The Study Information Sheet posed the following questions to the parents/guardians: "What is the purpose of this research?" Why are you invited to participate in this research?" "What is involved in this research?" "Is there any danger?" "How does this research help you?" The parent/guardian signed the Written Consent Form, permitting their child to participate in the study.

\section{Author details}

${ }^{1}$ Department of Nutrition and Dietetics, International Medical University, Kuala Lumpur 57000, Malaysia. ${ }^{2}$ Fonterra Research and Development Centre, Palmerston North, New Zealand. ${ }^{3}$ Faculty of Medicine and Health Sciences, Universiti Putra Malaysia, Serdang 43400, Malaysia.

\section{Received: 29 June 2016 Accepted: 19 November 2016} Published online: 01 December 2016

\section{References}

1. Palmano K, Rowan A, Guillermo R, Guan J, McJarrow P. The role of gangliosides in neurodevelopment. Nutrients. 2015;7:3891-913.

2. Wang B. Molecular mechanism underlying sialic acid as an essential nutrient for brain development and cognition. Adv Nutr. 2012;3:465S-72S.

3. Murphy T, Dias GP, Thuret S. Effects of diet on brain plasticity in animal and human studies: mind the gap. Neural Plasticity. 2014;563160. http://dx.doi.org/10.1155/2014/563160.

4. Haselhorst $U$, Krusche A, Schenk $H$, Hantke $H$. The influence of gangliosides on active conditioning avoidance-response on the 2 way shuttle box. Biomedica Biochimica Acta. 1988:47:475-80.

5. Mei ZT, Zheng JZ. Effects of exogenous gangliosides on learning and memory in rats. Jpn J Physiol. 1993;43:S295-9.

6. Silva RH, Bellot RG, Vital M, Frussa R. Effects of long-term ganglioside GM1 administration on a new discriminative avoidance test in normal adult mice. Psychopharmaco. 1997;129:322-8.

7. McJarrow P, Schnell N, Jumpsen J, Clandinin T. Influence of dietary gangliosides on neonatal brain development. Nutr Rev. 2009;67:451-63.
8. Wang B, Yu B, Karim M, Hu H, Sun Y, McGreevy P, et al. Dietary sialic acid supplementation improves learning and memory in piglets. Am J Clin Nutr. 2007;85:561-9.

9. Scholtz SA, Gottipati BS, Gajewski BJ, Carlson SE. Dietary sialic acid and cholesterol influence cortical composition in developing rats. J Nutr. 2013;143:132-5.

10. Reis MM, Bermingham EN, Reis MG, Deb-Choudhury S, MacGibbon A, Fong $B$, et al. Effect of dietary complex Lipids on the biosynthesis of piglet brain gangliosides. J Agric Food Chem. 2016;64:1245-55.

11. Park EJ, Thomson AB, Clandinin MT. Protection of intestinal occludin tight junction protein by dietary gangliosides in lipopolysaccharide-induced acute inflammation. J Pediatr Gastroenterol Nutr. 2010;50:321-8.

12. Li SC, Chien JL, Wan CC, Li YT. Occurrence of glycosphingolipids in chicken egg yolk. Biochem J. 1978;173:697-9.

13. Saito M, Rosenberg A. Glycolipids and their developmental patterns in chick thigh and leg muscles. J Lipid Res. 1982;23:3-8.

14. Nakamura K, Ariga T, Yahagi T, Miyatake T, Suzuki A, Yamakawa T. Interspecies comparison of muscle gangliosides by two-dimensional thinlayer chromatography. J Biochem. 1983;94:1359-65.

15. Saito M, Kitamura H, Sugiyama K. Liver gangliosides of various animals ranging from fish to mammalian species. Com Biochem Phys B. 2001;129:747-58.

16. Fong B, Norris C, Lowe E, McJarrow P. Liquid chromatography-highresolution mass spectrometry for quantitative analysis of gangliosides. Lipids. 2009;44:867-74.

17. Giuffrida F, Elmelegy IM, Thakkar SK, Marmet C, Destaillats F. Longitudinal Evolution of the Concentration of Gangliosides GM3 and GD3 in Human Milk. Lipids. 2014:49:997-1004.

18. Ma L, Liu X, MacGibbon AKH, Rowan A, McJarrow P, Fong BY. Lactational changes in concentration and distribution of ganglioside molecular species in human breast milk from Chinese mothers. Lipids. 2015;50:1145-54.

19. Ma L, MacGibbon AKH, Jan Mohamed HJB, Loy S, Rowan A, McJarrow P, et al. Determination of ganglioside concentrations in breast milk and serum from Malaysian mothers using a high performance liquid chromatography-mass spectrometry-multiple reaction monitoring method. Int Dairy J. 2015;49:62-71.

20. Pan $\mathrm{XL}$, Izumi T. Variation of the ganglioside compositions of human milk, cow's milk and infant formulas. Early Hum Dev. 2000:57:25-31.

21. Fong B, Norris C, McJarrow P. Liquid chromatography-high-resolution electrostatic ion-trap mass spectrometric analysis of GD3 ganglioside in dairy products. Int Dairy. 2011;21:42-7.

22. Sánchez-Díaz A, Ruano MJ, Lorente F, Hueso P. A critical analysis of total sialic acid and sialoglycoconjugate contents of bovine milk-based infant formulas. J Pediatr Gastroenterol Nutr. 1997;24:405-10.

23. Sorensen LK. A liquid chromatography/tandem mass spectrometric approach for the determination of gangliosides GD3 and GM3 in bovine milk and infant formulae. R Commun Mass Sp. 2006;20:3625-33.

24. Pham PH, Duffy TL, Dmytrash AL, Lien WW, Thomson AB, Clandinin MT. Estimate of dietary ganglioside intake in a group of healthy Edmontonians based on selected foods. J Food Comp Analysis. 2011;24:1031-7.

25. Nicolae I, Nicolae CD, Coman OA, Stefanescu M, Coman L, Ardeleanu C. Serum total gangliosides level: clinical prognostic implication. Romanian J Morphol Embryol. 2011:52:1277-81.

26. Fong BY, Ma L, Khor GL, van der Does $Y$, Rowan A, McJarrow $P$, and MacGibbon AKH. Ganglioside composition in beef, chicken, pork, and fish determined using liquid chromatogrphy-high resolution mass spectrometry. J. Agric. Food Chem. 2016;64:6295-305.

27. World Health Organization. WHO Child Growth Standards. Methods and Development. Geneva: WHO; 2006.

28. Department of Statistics Malaysia. Report of Household Income and Basic Amenities Survey 2014. https://www.statistics.gov.my. Accessed 15 Mar 2016.

29. National Coordinating Committee for Food and Nutrition (NCCFN). Recommended Nutrient Intakes for Malaysia. Putrajaya: Ministry of Health, Malaysia; 2005

30. Vesper H, Schmelz EM, Nikolova-Karakashion MN, Dillehay DL, Lynch DV Merrill Jr AH. Sphingolipids in food and the emerging importance of sphingolipids to nutrition. J Nutr. 1999;129:1239-50.

31. Miklavcic JJ, Schnabl KL, Mazurak VC, Thomson ABR, Clandinin MT. Dietary ganglioside reduces proinflammatory signaling in the intestine. J Nutr Metab. 2012;280286. http://dx.doi.org/10.1155/2012/280286.

32. Senn HJ, Orth M, Fitske E, Wieland H, Gerok W. Gangliosides in normal human serum. Concentration, pattern and transport by lipoproteins. Eur J Biochem. 1989;181:657-62 
33. Kolter T. Ganglioside Biochemistry. International Scholarly Research Network (ISRN) Biochemistry. 2012;506160 doi:10.5402/2012/506160.

34. Gurnida DA, Idjradinata P, Muchtadi D, Sekarwana N, Fong B, McJarrow $P$, et al. Diet-induced changes in serum ganglioside spectrum patterns in 6month-old infants. Majalah Kedokteran Bandung (MKB). 2012;44:240-4.

35. Miklavcic JJ, Shoemaker GK, Schnabl KL, Larsen BM, Thomson AB, Mazurak VC, et al. Gangliosideintake increases plasma ganglioside content in human participants. J Parenter Enteral Nutr. http://dx.doi.org/0148607115620093.

36. Svennerholm L. Ganglioside designation. Adv Exp Med Biol. 1980;125:11-9.

Submit your next manuscript to BioMed Central and we will help you at every step:

- We accept pre-submission inquiries

- Our selector tool helps you to find the most relevant journal

- We provide round the clock customer support

- Convenient online submission

- Thorough peer review

- Inclusion in PubMed and all major indexing services

- Maximum visibility for your research

Submit your manuscript at www.biomedcentral.com/submit 